4.

Derecho procesal civil 

Revista de Derecho

de la Pontificia Universidad Católica de Valparaíso

XXXI (Valparaíso, Chile, 2 Semestre de 2008)

[pp. 369 - 402]

\title{
LA EJECUCIÓN PROVISIONAL DE LAS SENTENCIAS
}

[The Provisional Enforcement of Rulings]

\author{
Óscar Silva Álvarez* \\ Pontificia Universidad Católica de Valparaíso
}

\begin{abstract}
RESUMEN
Dentro de la corriente reformista del proceso civil en Chile, un lugar importante debería estar ocupado por la figura de la ejecución provisional de las sentencias judiciales, como una manifestación del derecho a la tutela judicial efectiva y un instrumento para el acortamiento de los tiempos en el proceso. El presente artículo contiene un examen teórico a la figura de la ejecución provisional, y establece las reglas técnicas de su configuración legal. También analiza los aislados casos de tal figura existentes en la legislación chilena.

Palabras Clave: Reforma procesal civil - Ejecución provisional - Doble instancia.
\end{abstract}

\begin{abstract}
Within the reformist current of the civil process in Chile, an important place should be occupied by the figure of the provisional enforcement of the judgments, like an manifestation from the right to the effective judicial tutelage and a instrument in the reduction of the times in the process. The present article outlines a theoretical examination to the figure of the provisional enforcement and establishing the technical rules for its legal configuration. Also examines the isolated cases of the figure existent in the Chilean legislation.

KeYwords: Civil Procedural Reform - Provisional Enforcement - Double Instance.
\end{abstract}

* Profesor contratado de Derecho procesal civil en la Pontificia Universidad Católica de Valparaíso y en la Universidad de Viña del Mar. Estudiante de Doctorado en derecho en la Pontificia Universidad Católica de Valparaíso. Dirección de correo electrónico: oscar.silva.a@gmail.com 


\section{CONSIDERACIONES PRELIMINARES**}

La influencia del factor tiempo sobre la obtención de una tutela judicial efectiva es, quizás, la más determinante en el ámbito procesal. En efecto, se trata de "una de las ideas más recurridas que están detrás de todo proceso

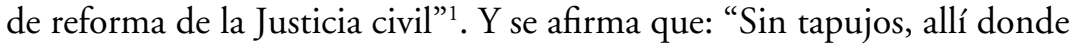
no haya instrumentalidad eficaz y justa, esse quid, será cualquier cosa, menos proceso" 2 .

En nuestro país, desde hace algún tiempo se está incubando y desarrollando la idea de sustituir nuestro actual régimen procesal civil, que ya supera los cien años de edad, por uno estructurado sobre bases bastante diferentes. Se trata de la última gran parcela no invadida por la tendencia reformista, que ya ha sustituido, íntegramente, la justicia penal, de familia y, más recientemente, laboral.

La radical transformación que se avecina, constituye la respuesta que el Estado pretende dar a un sistema procesal civil (orgánico y procedimental) que, objetivamente, se encuentra colapsado, y que obliga a someter las pretensiones de los ciudadanos a un camino tan extenso, que muchas veces torna en irrisoria la posibilidad de obtener una efectiva protección del derecho del justiciable.

Dentro de los objetivos perseguidos por la reforma procesal civil que se está gestando, uno de los principales es, precisamente, la disminución radical del tiempo que media entre el inicio de un procedimiento y la ejecución de lo decidido por el tribunal al resolver la controversia. De ello da cuenta el FPC, constituido como la instancia más importante de discusión y gestión del nuevo sistema procedimental, y cuyo informe final señala al respecto que: "es sin duda, la lentitud de los procesos uno de los aspectos más complejos presentes en nuestra actual justicia civil. Según uno de los pocos estudios existentes relativo a la duración promedio de los diversos procedimientos, la extensión de un juicio ordinario es en promedio de 2009 días; de un juicio ejecutivo, 785 días; y de un juicio

** Tabla de abreviaturas: APCPC.: = Anteproyecto de Código Procesal Civil (Chile) FPC $=$ Foro Procesal Civil (Chile); LBPA. = Ley No 19.880, sobre bases de los procedimientos que rigen los actos de los órganos de la Administración del Estado; LECEsp. $(2000)=$ Ley de Enjuiciamiento Civil del año 2000 (España); RDPC. = Rivista di Diritto Processuale Civile.

${ }^{1}$ Hinojosa Segovia, Rafael - Palomo Vélez, Diego, La apuesta de la nueva Ley de Enjuiciamiento Civil Española por la revalorización de la importancia del enjuiciamiento de primer grado: La nueva regulación de la ejecución provisional de las sentencias, en Ius et Praxis 2 (Talca, 2006), p. 126.

${ }^{2}$ Pérez Ragone, Álvaro, Introducción al estudio de la tutela anticipatoria, en Revista del Proceso 81 (São Paulo, 1999), p. 135. 
sumario, 707 días. Si a lo anteriormente dicho unimos la idea que justicia retrasada es justicia denegada, la necesidad de reformar nuestra justicia civil se nos presenta como un profundo deber al cual debemos entregar nuestros mayores esfuerzos. La realidad descrita choca frontalmente con el anhelo y el deber de contar con una justicia civil pronta, eficaz, y accesible al ciudadano común"3.

La tan anhelada obtención de la tutela judicial efectiva es, entonces, la inspiración más transversal de todo sistema procesal moderno, y es dicho carácter transversal el que permite explicar muchas de las instituciones -o modalidades de instituciones- que, frecuentemente, se presentan en las legislaciones procesales.

Dentro de dichas instituciones, este trabajo se ocupará de una en particular: la ejecución provisional de las sentencias definitivas ${ }^{4}$. Se trata de uno de los mecanismos que se encuentran diseñados para permitir el adelantamiento de la tutela otorgada por la sentencia, antes que ésta se encuentre a firme, y que pretende ser incorporado a nuestra nueva legislación procesal. Ello, a pesar de que en el APCPC. no la regula mayormente, limitándose a sentar el principio de ejecutividad provisional de las sentencias definitivas e interlocutorias 5 .

Esta constatación es el primer indicio de un cambio de mentalidad del legislador, que va más allá de una mera sustitución de un sistema procesal por otro. Es notorio que la ineficacia inmediata de las resoluciones judiciales, establecida como regla general, es la solución dada por el legislador que privilegia la seguridad por sobre la efectividad de dichas resoluciones.

El objeto es mostrar un panorama general de la institución, perfilando sus contornos y planteando algunas interrogantes que se vinculan tanto con aspectos netamente técnicos de la figura, como con principios procesales. Además, como veremos, se hará presente que la institución no es

${ }^{3} \mathrm{VV}$. AA, Informe final del Foro para la Reforma Procesal Civil Chilena (Santiago, 2006), documento inédito.

${ }^{4} \mathrm{He}$ optado por seguir la denominación expresada, consciente de las discusiones existentes con relación a la correcta manera de llamar a esta institución, y de la cual me haré cargo, someramente, más adelante.

${ }^{5}$ En efecto, el artículo 18 del mencionado anteproyecto dispone, en su inciso 2०: "Las sentencias definitivas e interlocutorias podrán cumplirse provisionalmente, aun cuando no se encontraren firmes o ejecutoriadas, salvo que el legislador disponga expresamente lo contrario". Sin embargo, el FPC discurre mayormente en su Informe Final, sentando las bases de su reglamentación en términos muy similares, como veremos, a la Ley de Enjuiciamiento Civil española del año 2000.

${ }^{6}$ Barros Leonel, Ricardo De, A eficacia imediata da sentença e as reformas do Código de Processo Civil, en Revista del Proceso 119 (São Paulo, 2005), p. 125. 
ajena a nuestro ordenamiento jurídico, aunque no se regula de manera orgánica.

Así entonces, comenzaré abordando la institución de la ejecución provisional desde lo conceptual, pasando por su naturaleza jurídica, sus fundamentos y objetivos; todos ellos tópicos que no están completamente claros ni uniformados en una sola dirección.

Posteriormente, analizaré las que, considero, son las reglas técnicas más importantes entre las cuales debe optar el legislador en el momento de configurar la institución en un orden jurídico concreto.

El trabajo continuará señalando los casos en que está presente, desde una perspectiva funcional, la ejecución provisional en el derecho nacional; para concluir con una visión crítica de la regulación que, de la figura en cuestión, hace el APCPC.

\section{CONCEPTO, NATURALEZA JURÍDICA, FUNDAMENTOS Y OBJETIVOS DE LA EJECUCIÓN PROVISIONAL}

Existen diversas definiciones de lo que debe entenderse por ejecución provisional o provisoria de la sentencia definitiva. Federico Carpi señala que es "la anticipación de la eficacia ejecutiva de la sentencia o de otras providencias judiciales, respecto al momento y al grado de madurez que la ley considera como normal"7. Manuel Ortells Ramos, por su parte, la define como "el proceso de ejecución por el que el órgano jurisdiccional realiza una serie de actividades, para acomodar la realidad exterior a lo establecido en el título ejecutivo -una resolución sobre el fondo carente de firmeza- con incidencia en la esfera jurídica y patrimonial de quien venga obligado por el título, quedando supeditada la permanencia de dicha actividad ejecutiva a lo que resulte del recurso interpuesto contra la resolución definitiva".

Desde otro punto de vista, Osvaldo Gozaíni, poniendo el acento en el carácter de prerrogativa de una parte más que en el efecto mismo de la institución, indica que: "Por ejecución provisional se entiende la facultad que tiene la parte para requerir el cumplimiento de una sentencia condenatoria que aún no se encuentra firme" . En similar sentido, para Romero Seguel consiste en la posibilidad de "cumplir los efectos de la sentencia como si

${ }^{7}$ CARPI, Federico, La provvisoria esecutorietà della sentenza (Milano, 1979), p. 3. Traducción del autor.

${ }^{8}$ Ortells Ramos, Manuel, Derecho Procesal Civil (6a edición, Navarra, 2005), p. 896.

${ }^{9}$ Gozaíni, Osvaldo, La ejecución provisional en el proceso civil, en Revista Peruana de Derecho Procesal 3 (Lima, 1998), p. 81. 
ella estuviera firme, permitiendo que el actor pueda empezar a gozar del contenido total de la pretensión admitida en la sentencia, aunque exista un recurso pendiente" ${ }^{10}$.

Finalmente, Luis Caballol afirma que: "la ejecución provisional es la institución procesal mediante la cual se atribuye eficacia a una resolución definitiva sobre el fondo carente de firmeza, quedando subordinada la permanencia de los efectos producidos a lo que resulte del recurso" ${ }^{11}$.

Punto aparte merece la discusión en torno a lo adecuado o no que puede resultar el adjetivo provisional o provisorio. Un importante sector de la doctrina ha criticado el calificativo de provisional, que lleva la ejecución en comento. Así, Carnelutti habla de ejecución in mediata ${ }^{12}$, ya que la ejecución de una sentencia apelable no es más provisional de lo que puede ser la ejecución de una sentencia de apelación. El mismo autor, en otra de sus obras cumbres, varía su postura, señalando que: "técnicamente, la palabra provisional debe sustituirse por la palabra condicional" 13 , considerando la reforma de la sentencia apelada como condición resolutoria de la ejecución practicada.

A su turno, Luiz Guilherme Marinoni, quien afirma que los actos ejecutivos, al alterar la realidad física, mal pueden ser catalogados como provisorios $^{14}$, propone la denominación de sentencia provisoria con efectos inmediatos, aunque también utiliza el término ejecución inmediata, pues ilustra el hecho que la sentencia puede producir sus efectos propios inmediatamente ${ }^{15}$. El mismo autor sostiene que el carácter provisorio es predicable del título sobre el cual se funda la ejecución, mas no la ejecución en sí misma ${ }^{16}$.

José Da Silva Pacheco añade, por su parte, que la ejecución es pro-

${ }^{10}$ Romero Seguel, Alejandro, Curso de Derecho Procesal Civil. La acción y la protección de los derechos (Santiago, 2006), I, p. 42.

${ }^{11}$ Caballol, Luis, La ejecución provisional en el proceso civil (Barcelona, 1993), p. 47.

${ }^{12}$ Carnelutti, Francesco, Instituciones del Proceso Civil (Buenos Aires, 1960), II, p. 137. Idéntica opinión encontramos en SATTA, Salvatore - Punzi, Carmine, Diritto processuale civile (13 a edición, Padova, 2004), p. 378.

${ }^{13}$ Carnelutti, Francesco, Sistema de Derecho Procesal Civil (Buenos Aires, 1944), IV, p. 441.

${ }^{14}$ Marinoni, Luiz Guilherme, A execuçao "provisória" da sentença, en MarinOnI, Luiz Guilherme - DiDIER, Fredie (coordinadores), A segunda etapa da reforma processual civil (São Paulo, 2001), p. 20.

${ }^{15}$ Ibíd., p. 21.

${ }^{16}$ Marinoni, Luiz Guilherme, Antecipaçao da tutela (4a edición, São Paulo, 1998), p. 177. 
visoria porque la sentencia, aunque es ejecutable, no es formalmente intocable ${ }^{17}$.

Todas estas definiciones, a pesar de algunas distinciones que, desde una perspectiva funcional, califico de menores, dejan al descubierto algunas propiedades o características distintivas del instituto, tales como la anticipación en la obtención de la tutela judicial y la carencia de firmeza de la resolución ejecutada.

Por lo demás, la ejecución provisional de las sentencias es una figura demostrativa de la distinción nítida que existe entre la eficacia de la sentencia y la autoridad de cosa juzgada de la misma. Como bien afirma Liebman, en relación al efecto suspensivo del recurso de apelación contra una sentencia: "la suspensión, de hecho, no cancela, no suprime, no elimina la eficacia, sino que sólo le impide operar mientras dura la causa de dicha suspensión; la comprime temporalmente y la deja latente, lista para volverse operante cuando el motivo por el cual la suspensión fue impuesta deje de existir. Sin embargo ¿qué mayor prueba puede ser de la existencia de aquella eficacia, la de la norma que dispone su suspensión? ¿Es quizás posible suspender aquello que no existe?" 18

Ahora bien, el panorama relativamente pacífico en el ámbito de la definición de ejecución provisional, da paso a una mayor dificultad al intentar establecer cuál es su naturaleza jurídica, al extraer los fundamentos de su existencia y, más aún, al definir cuáles son los objetivos perseguidos con su instauración dentro de un sistema procesal. Veamos, en el mismo orden propuesto, cada uno de estos tópicos.

\section{Naturaleza jurídica de la ejecución provisional.}

De las definiciones antes entregadas, podrán surgir dudas acerca de cuál es la naturaleza jurídica de la institución de la ejecución provisional. En efecto, ha existido discusión en relación al punto, debatiéndose la institución entre un sector que le atribuye una naturaleza netamente ejecutiva, y otro que la emparienta íntimamente con las medidas cautelares.

Carpi, quien niega la naturaleza cautelar de la ejecución provisional, a pesar de reconocerle una función de tal carácter, justifica su parecer, fundamentalmente, en la falta de instrumentalidad ${ }^{19}$ de la institución,

${ }^{17}$ Silva Pacheco DA, José, Açoes executivas e execuçao de sentença (Río de Janeiro, 1957), p. 329.

${ }^{18}$ Liebman, Enrico Tulio, Sentenza e Cosa Giudicata: recente polemiche, en RDPC. 35 (Segunda serie), parte I (1980), p. 4.

19 "No puede ser afirmada la naturaleza cautelar típica de la ejecución provisoria, por varios motivos. Ante todo, falta la instrumentalidad, propia de las disposiciones cautelares. Es evidente que la anticipación de la ejecutoriedad importa la creación de 
en relación a la que sí tienen, indudablemente, las medidas cautelares, las cuales "crean una situación inconcebible fuera de una controversia pendiente o inminente, y se extinguen si se extingue el proceso o éste no es promovido" 20 .

Sin embargo, la mayor diferencia entre una medida cautelar y la ejecución provisional consiste en la verosimilitud del derecho, o "fumus boni iuris". En efecto y, como afirma Gozaíni, "mientras en las medidas cautelares es suficiente una apariencia del derecho, en la ejecución dispuesta queda de manifiesto una declaración sobre su existencia" ${ }^{21}$. Esto, que pareciera divorciar las medidas cautelares de nuestra figura analizada, es, empero, nuevamente moderado al acercarse a éstas, en cuanto al fin de evitar el peligro en la demora de la ejecución o periculum in mora ${ }^{22}$.

Efectivamente, también pienso que la ejecución provisional, si bien tiene una finalidad de aseguramiento de la tutela perseguida y declarada por la sentencia, difiere importantemente de las medidas cautelares. Éstas últimas están destinadas, ab initio, a desaparecer una vez que el resultado del juicio se entienda garantizado, o cuando, por alguna razón, ya no tengan razón de ser, al concluir el procedimiento en virtud del cual ellas surgieron. El propio artículo $301 \mathrm{CPC}$. destaca esta característica, al señalar que las medidas precautorias son "esencialmente provisionales"; principio mantenido por el APCPC. en su artículo 178, en términos muy similares.

La ejecución provisional, en cambio, desde un punto de vista lógico tiende hacia la estabilidad y la consolidación. De otra manera, sería absurdo entregarle la posibilidad a la parte vencedora de ejecutar una resolución antes que ésta haya sido cubierta por la cosa juzgada.

No obstante todo lo antes señalado, más adelante se observará que la ejecución provisional, tal como es concebida en algunos sistemas, es preponderantemente cautelar antes que ejecutiva propiamente $\mathrm{tal}^{23}$.

\section{Fundamentos y objetos de la ejecución provisional.}

No pueden caber dudas razonables al considerar que la ejecución forma

los presupuestos para la efectiva realización de la tutela otorgada por la sentencia de mérito, pero precisamente porque de realización debe tratarse, es la sanción misma que es ejecutada”. CARPI, Federico, cit. (n. 7), p. 49. Traducción del autor.

${ }^{20}$ CARPI, Federico, cit. (n. 7), p. 50. Traducción del autor.

${ }^{21}$ Gozaíni, Osvaldo, cit. (n. 9), p. 90.

${ }^{22}$ Ibíd.

${ }^{23}$ Dicha constatación relativiza, por ende, la afirmación que la tutela anticipada -de la cual es especie la ejecución provisional-, genere una forma de protección diversa que la que surge con la concesión de una medida precautoria; la que, sin embargo, sí es correcta en el caso del derecho chileno. Véase, al respecto, Romero Seguel, Alejandro, cit. (n. 10), p. 42. 
parte integrante del derecho a una tutela judicial efectiva, pues constituye la consecuencia lógica del conocimiento, por parte de un tribunal, de las pretensiones jurídicas de los ciudadanos; ello, descontando que la mencionada tutela es la finalidad principal del proceso ${ }^{24}$. Por ello se ha dicho: "El derecho a la ejecución como la faz del derecho fundamental procesal de acción para la satisfacción real del titular incluye para éste la oportuna satisfacción" 25 .

Es más, cuando se proyecta la idea de la tutela judicial efectiva en el procedimiento ejecutivo, fácil es comprender que: "es el aspecto de la tutela jurisdiccional en que se mide, con mayor precisión, la eficiencia de un sistema procesal como medio para la realización de la tutela en sí" 26 . La actividad jurisdiccional dirigida a la realización del derecho que, desde el punto de vista social aparece como una función, desde el punto de vista jurídico se erige como una verdadera obligación jurídica del Estado, a través de los órganos jurisdiccionales; obligación que, para el ciudadano, es un derecho público subjetivo consistente en que, una vez que el derecho sea (o bien se suponga) legalmente cierto, puede pretenderse la prestación de la actividad jurisdiccional, dirigida a la realización coactiva del derecho ${ }^{27}$

Sin embargo, no es tan diáfano el panorama al centrarnos en la figura de la ejecución provisional de la sentencia de primera instancia.

La ejecución provisional, desde un punto de vista empírico, puede tener un acento ejecutivo propiamente tal, o uno más centrado en el carácter cautelar de la institución, asegurando el resultado del juicio. Siempre en este ámbito, la mayor diferencia entre los distintos sistemas que establecen la ejecución provisional consiste en la posibilidad o no de vender los bienes embargados del deudor, interrogante que se conecta con la finalidad misma de la ejecución provisional -satisfacción

${ }^{24}$ Salgado Carrero, Celestino, El derecho a la ejecución de las sentencias como manifestación del derecho fundamental a la tutela judicial efectiva, en Revista del Poder Judicial 51 (Madrid, 1998), p. 71. El mismo autor (p. 72) añade que: "El derecho a la tutela judicial efectiva, de forma sintética, no supone satisfacción de las pretensiones de fondo del justiciable, sino que consiste en que los Jueces y Tribunales le permitan acceder a la jurisdicción, ser oído, proponer y practicar prueba y obtener una resolución fundada en Derecho, que verse sobre las pretensiones planteadas en juicio".

${ }^{25}$ Pérez RagOne, Álvaro, El acceso a la tutela ejecutiva del crédito, en Silva, José - García, José - Leturia, Francisco (editores), Justicia Civil y Comercial: una reforma pendiente. Bases para diseño de la Reforma Procesal Civil (Santiago, 2006), p. 495.

${ }^{26}$ Micheli, Gian Antonio, La tutela del diritto di credito nel processo esecutivo, en VV. AA, Atti del Congresso internazionale di Diritto Processuale Civile (Padova, 1953), p. 90. Traducción del autor.

${ }^{27}$ Rocco, Ugo, Trattato di Diritto Processuale Civile (Torino, 1959), IV, p. 5. 
inmediata del crédito o mera seguridad para el acreedor-. En la mayoría de las legislaciones se permite dicha venta ${ }^{28}$.

En cuanto poner el énfasis en el aspecto cautelar del instituto, un autor, adherente a esta concepción, señala que: "En la ejecución provisoria, el efecto suspensivo de los recursos, aun atenuado, todavía existe, y opera en la fase final de la ejecución cuando, estando asegurado el juicio, la espera no produce más perjuicios" ${ }^{29}$. Sin embargo, en la vereda contraria, para Marinoni la ejecución provisional (o ejecución inmediata en sus términos), en la perspectiva que debe ser vista actualmente, nada puede tener que ver con el aseguramiento del resultado del juicio, o con el aseguramiento del derecho de crédito, ya que su compromiso es con la tempestividad de la tutela jurisdiccional. En otras palabras, la ejecución inmediata, para tener alguna razón de ser, debe permitir la realización inmediata del derecho del actor ${ }^{30}$.

Por otro lado, y a pesar que ningún autor niega la utilidad de la institución para favorecer la tutela judicial efectiva ${ }^{31}$, ésta es considerada, por la mayor parte de la doctrina, como una cuestión de política legislativa, sin que su establecimiento o supresión afecten, en su esencia, el derecho a la mencionada tutela judicial efectiva ${ }^{32}$. En consecuencia, tan constitucional es establecer la ejecución provisional, como excluirla.

a) La ejecución provisional como manifestación del derecho a una tutela judicial efectiva. Como afirma un autor, "con cada dilación en la ejecución de una sentencia está indisolublemente conectado un daño, el cual no es sino el aspecto negativo de aquel interés de actuar que, a su vez, es el presupuesto de cada demanda judicial"33. Por su parte, Marinoni da cuenta del enorme conflicto que existe entre el derecho a la tempestividad de la tutela jurisdiccional y el derecho a la cognición defi-

${ }^{28}$ Kerameus, Konstantinos, Enforcement Proceedings, en Capelletti, Mauro (editor), International Encyclopedia of Comparative Law (Dordrecht, 2002), XVI, cap. $10^{\circ}$, p. 24.

${ }^{29}$ Liebman, Enrico Tulio, Processo de Execuçao (São Paulo, 1968), p. 58. Traducción del autor.

${ }^{30}$ MarinONi, Luiz Guilherme, cit. (n. 14), p. 25.

${ }^{31}$ Véase Hinojosa Segovia, Rafael - Palomo Vélez, Diego, cit. (n. 1), p. 133.

${ }^{32}$ V. gr., Ortells Ramos, Manuel, cit. (n. 8), p. 897; de la Oliva Santos, Andrés - Díez-Picaso Giménez, Ignacio - Vegas Torres, Jaime, Derecho Procesal Civil: Ejecución forzosa. Procesos especiales ${ }^{3}$ (Madrid, 2005), p. 364; Romero Seguel, Alejandro, La cosa juzgada en el proceso civil chileno. Doctrina y jurisprudencia (Santiago, 2002), p. 28.

${ }^{33}$ FINZI, Enrico, Questioni controverse in tema di esecuzione provvisoria, en RDPC. 3, parte I (1926), p. 49. Traducción del autor. 
nitiva (derecho de defensa) ${ }^{34}$. El mismo autor sostiene, que dicha tensión debe resolverse teniendo a la vista, fundamentalmente, la evidencia del derecho del actor. Dicha evidencia, la mayor parte de las veces, se produce cuando el juez está en condiciones de dictar sentencia. Entretanto, si el juez declara la existencia de un derecho, no hay razón para que el actor sea obligado a soportar el tiempo del recurso ${ }^{35}$.

Entregando pautas para la determinación de la solución al conflicto, el juez debe considerar la probabilidad del éxito del recurso yla relación entre el daño que puede ser impuesto al demandado por la ejecución inmediata, versus el daño que puede ser generado al actor por la ausencia de esta ejecución. Sólo ante un recurso manifiestamente fundado es admisible una suspensión de la ejecución; si se trata de un recurso no manifiestamente fundado o infundado, debe atenerse al daño que pueda producirse a una u otra parte por la ejecución o la suspensión de ésta ${ }^{36}$

Siempre bajo la misma óptica, la sentencia, como punto culminante de todo un recorrido procedimental, es un acto intrínsecamente legítimo y justo. Sin embargo, esta apreciación, que teóricamente no admite mayores reparos, se diluye al observar cómo es considerada la sentencia de primera instancia en el foro: un mero proyecto de la verdadera decisión, que será la de segunda instancia.

Sin embargo, lo anterior, a la luz de los hechos, la reforma o revocación de una sentencia de primera instancia es la excepción, en relación a la confirmación de la misma en sede de apelación. Si nos centramos en la realidad de nuestro país, puede observarse que las sentencias de primera instancia, en términos generales, son bastante respetadas por las Cortes de Apelaciones. En efecto, y según estadísticas aportadas por la Corporación Administrativa del Poder Judicial ${ }^{37}$ que consideran el tiempo que media entre el año 2005 y julio del año 2007, en la Corte de Apelaciones de Santiago fueron confirmadas 8.216 sentencias apeladas, mientras que sólo 461 fueron revocadas. En la Corte de Apelaciones de Valparaíso, 5.558 sentencias de primera instancia fueron confirmadas, mientras que sólo 584 recursos fueron acogidos. En la Corte de Apelaciones de San Miguel, la

${ }^{34}$ MarinONI, Luiz Guilherme, cit. (n. 14), p. 14.

${ }^{35}$ Ibíd. En contra, Finzi, Enrico, cit. (n. 33), p. 51.

${ }^{36}$ Ibíd., p. 32.

${ }^{37} \mathrm{El}$ estudio estadístico mencionado fue aportado al autor por la Corporación Administrativa del Poder Judicial, en soporte electrónico, y no se consideran en este trabajo los recursos de apelación que no concluyeron en sentencia definitiva, por ejemplo, por haber sido declarados desiertos, desistidos o prescritos. 
proporción respectiva es de 2.258 contra 252; mientras que en la Corte de Apelaciones de Concepción, es de 2.915 contra 516.

Diversas son las lecturas y conjeturas que pueden realizarse a partir de las estadísticas antes indicadas. Por lo pronto, tentador resulta afirmar que el recurso de apelación es objeto de abusos en su interposición por parte de las partes vencidas en los juicios, aunque ello en el entendido que la ponderación de los tribunales de alzada de cada recurso interpuesto es, generalmente, la adecuada. De otra manera no se podría comprender la cantidad considerablemente mayor de sentencias confirmadas, en relación a las que son modificadas o revocadas.

También es un dato objetivo a considerar a los efectos de abandonar los miedos que surgen al pensar en la ejecución provisional, pues estadísticamente al menos, muchos más son los casos en que la sentencia de primera instancia es confirmada, que aquellos en que es reformada o revocada; por ende, la regla general, desde una visión empírica, es que la actividad ejecutiva provisional termina siendo, la mayor parte de las veces, definitiva.

b) La ejecución provisional como forma de potenciar el juicio en su primer grado y desestimar la interposición de recursos injustificados. Frecuente es encontrar opiniones que sostienen, como uno de los principales fundamentos de la consagración de un régimen de ejecución provisional de las sentencias como regla general, el de potenciar la sentencia de primer grado ${ }^{38}$, por la vía de la efectividad inmediata de la sentencia, así como por una posible disuasión de la interposición de recursos injustificados. Ello, a pesar que hay que preguntarse si la tan enfatizada valorización del juicio de primer grado es, per se, una justificación suficiente, en el plano lógico y sistemático, para imponer, como regla general, el automatismo generalizado de los efectos ejecutivos inmediatos ${ }^{39}$.

Siempre en este ámbito, suele mencionarse como uno de los fines perseguidos por la institución procesal de la ejecución provisional, tanto por la doctrina como en la historia legal de su establecimiento ${ }^{40}$, la disuasión de la parte vencida del deseo de alargar el juicio innecesariamente, mediante la interposición injustificada del recurso de apelación en contra de una sentencia que le es desfavorable, y aprovechando la concesión de dicho recurso en ambos efectos. Marinoni, desde la perspectiva del proceso civil brasileño, afirma que: "si la sentencia del juez de primer

${ }^{38}$ Carpi, Federico, cit. (n. 7), p. 17.

${ }^{39}$ En tal sentido, Comoglio, Luigi Paolo, L'esecuzione provvisoria della senten$z a$ di primo grado, en VV. AA, Le Riforme della giustizia civile (2a edición, Torino, 2000), p. 416.

${ }^{40}$ Así ocurrió, por ejemplo, en las reformas procesales civiles española e italiana. 
grado estuviese dotada de ejecutividad inmediata, no sólo sería innecesaria la tutela anticipatoria final, sino que estaría prácticamente eliminada la problemática del abuso del derecho a recurrir en contra de la sentencia" ${ }^{41}$. Cordón Moreno, analizando la institución en España, no tiene problemas en señalar que la ejecución provisional "intenta evitar que el deudor condenado alargue el proceso interponiendo recursos infundados con la única finalidad de retrasar el cumplimiento de la condena" ${ }^{42}$. Comoglio, desde la realidad italiana, menciona el ca rácter sa ncio n a to rio de la ejecución provisional, con el fin de poner frenos significativos al abuso eventual de los instrumentos procesales ${ }^{43}$. Otros autores, finalmente, sostienen que: "Con indudable acierto se ha dicho que un sistema procesal avanzado debe arbitrar medios para evitar que la parte vencida pueda llegar a utilizar los recursos con un único fin dilatorio, alargando innecesariamente la duración del proceso y, por lo mismo, retrasando la ejecución, disponiendo del tiempo de la segunda instancia y de un eventual recurso extraordinario para lograr eludir su responsabilidad. Lo que se acostumbra llamar como uso de los recursos con ánimo torticero" ${ }^{44}$.

Como se ve, se trata de una apreciación que surge con mucha naturalidad. En efecto, si se entiende el uso del recurso como una manera de dilatar el cumplimiento de la sentencia, eliminándose dicho efecto, y permitiendo la ejecución provisional de la resolución impugnada, resulta plausible estimar que la parte vencida desistirá de su deseo de impugnar la resolución, salvo que estime que el recurso tiene buenas posibilidades de ser acogido.

Sin embargo, con la misma naturalidad, pero desde una posición diametralmente opuesta, podría afirmarse que el deudor, ante la existencia del instituto de la ejecución provisional, debería tender a impugnar la sentencia definitiva, en el entendido que es la única manera de, eventualmente, retrotraer los efectos derivados de la ejecución. La sola posibilidad de revocar un fallo puede ser un aliciente suficientemente atractivo para el litigante perdedor.

La conjetura anterior la planteo para mostrar que, la finalidad que se le atribuye a la ejecución provisional, como disuasivo de recursos injustificados es, a lo menos, bastante discutible. Se trata de un efecto cuya comprobación aparece como bastante difícil.

Por lo demás, resulta legítimo preguntarse cuál es el afán de reducir el número de recursos, considerando que su existencia es una vía para la

\footnotetext{
${ }^{41}$ MarinONi, Luiz Guilherme, cit. (n. 14), p. 9. Traducción del autor.

${ }^{42}$ Cordón Moreno, Faustino, El proceso de ejecución (Navarra, 2002), p. 65.

${ }^{43}$ Comoglio, Luigi Paolo, cit. (n. 39), p. 419.

${ }^{44}$ Hinojosa Segovia, Rafael - Palomo Vélez, Diego, cit. (n. 1), p. 139.
} 
mejora y establecimiento de la jurisprudencia, por mencionar sólo un aspecto. Independientemente que se discuta acerca de la naturaleza de derecho fundamental o no que pueda tener el acceso a la doble instancia en materia civil (pues en materia penal la respuesta afirmativa es más pacífica), es necesario considerarla, más bien, como un ordenamiento empírico de la disciplina legislativa, sugerido por una antigua y constante experiencia. Dicha experiencia enseña, que una suficiente aproximación de las decisiones a la realidad y la verdad, muy a menudo, no se puede conseguir con un primer pronunciamiento, sino que progresivamente, por corrección de los resultados obtenidos en este primer experimento ${ }^{45}$. Además, y como veremos inmediatamente, resulta discutible este efecto que, supuestamente, produciría la institución de la ejecución provisional de las sentencias.

Si traemos a la vista la realidad de España -país que convive con un sistema de ejecución provisional de fácil acceso desde el año 2000-, un reciente estudio sobre los efectos de la ejecución provisional en la disminución de los recursos demuestra, empíricamente, que el instituto tiene un efecto neutro sobre la interposición de apelaciones contra la sentencia ${ }^{46}$. En otros términos, desde la entrada en vigor de la Ley de Enjuiciamiento Civil española del año 2000, la tasa de apelaciones contra sentencias definitivas de primera instancia no ha variado sustancialmente.

Todo lo anteriormente mencionado nos conecta, nuevamente, con un

${ }^{45}$ Carpi, Federico, cit. (n. 7), pp. 13-14.

${ }^{46}$ Ramos Romeu, Francisco, ¿Reduce realmente la ejecución provisional la interposición de recursos injustificados? disponible en: http://www.indret.com/pdf/385_es.pdf (consulta: agosto de 2007). El mismo autor menciona 3 teorías explicativas de la supuesta disuasión que la ejecución provisional produce en el litigante perdedor, aunque no se inclina por ninguna en particular. La primera de ellas, denominada teoría la insolvencia, "postula que la ejecución provisional reduce los recursos injustificados porque el demandado condenado, aunque sabe que no tiene razón, sin ejecución provisional busca el recurso para ganar tiempo a fin de poner sus bienes a buen recaudo, cosa que ya no puede hacer cuando exista la ejecución provisional". La segunda, que llama teoría de la rentabilidad, "postula que la ejecución provisional reduce los recursos injustificados porque el demandado condenado, aunque sabe que no tiene razón, sin ejecución provisional busca el recurso para ganar tiempo a fin de poner sus bienes a buen recaudo, cosa que ya no puede hacer cuando exista la ejecución provisional”. Finalmente, una tercera postura, llamada teoría de la acomodación, "parte de que el tribunal que conoce del recurso, en comparación con un escenario en que no existe ejecución provisional, se mostrará mucho menos proclive a revocar la sentencia de instancia cuando ésta ya se ha ejecutado provisionalmente, por los gastos extra en que incurriría la Administración de Justicia para revocar la ejecución provisional y la posible responsabilidad personal del juez y del Estado por los daños que se hubieran causado al condenado injustamente". 
conflicto o colisión que se produce al situar en bandos opuestos el derecho a la cognición definitiva y el derecho a la tutela judicial efectiva. En mi opinión, esta colisión es más aparente que real. Si se analiza la estructura de la ejecución provisional, independientemente del sistema particular en la que se desenvuelva, se observa que está dispuesta, precisamente, como un medio que concilia perfectamente el derecho a un conocimiento cabal del asunto, con la pertinencia y oportunidad de la tutela otorgada por la sentencia definitiva. Desde otro punto de vista, y compartiendo en este campo lo afirmado por Marinoni, no se trata de privilegiar la posición del actor en detrimento de la posición del demandado, sino de establecer una regla muy importante para la "isonomía" (igualdad) de las partes en el juicio ${ }^{47}$. Una relectura de esta forma de concebir la ejecución provisional nos lleva, en último término, a afirmar que el instituto en análisis es una manifestación del afán de distribuir adecuadamente la carga de soportar los tiempos que conlleva el proceso.

c) Algunas notas sobre el doble grado de conocimiento. La existencia de un sistema orgánico de ejecución provisional de las sentencias hace necesario referirse, aunque sea brevemente, al tema del doble grado de conocimiento jurisdiccional. La discusión sobre el carácter de derecho fundamental que pueda o no tener la existencia de una doble instancia, hay que tener presente que dicha controversia está planteada principalmente en el derecho continental, toda vez que, en la tradición del "common law", histórica y culturalmente es extraña la exigencia de un doble grado, debido al vínculo del precedente y al principio denominado "finality" (que incide sobre la formación de la cosa juzgada, imponiendo, como regla general, considerar ya como definitiva y ejecutiva la decisión de primer grado ${ }^{48}$.

Como sea, el tópico no carece de importancia, toda vez que, junto al principio de la tutela judicial efectiva se levanta otro, de tanta importancia como el primero, y que es el derecho al debido proceso jurisdiccional. Tradicionalmente se ha entendido que la posibilidad de un doble conocimiento del asunto colabora en el objetivo de alcanzar la decisión más justa posible y que, más que ello, forma parte del concepto de debido proceso. Desde un punto de vista ideológico, cierto es que en el plano de la técnica del proceso, el doble grado se justifica a condición de estimar la segunda decisión más atendible que la primera ${ }^{49}$.

No obstante lo anterior, no es menos razonable estimar que, en el

${ }^{47}$ Marinoni, Luiz Guilherme, cit. (n. 14), p. 26.

${ }^{48}$ Así lo afirma Comoglio, Luigi Paolo, Il doppio grado di giudizio nelle prospettive di revisione costituzionale, en RDPC. 59 (Segunda serie), parte II (1999), p. 329.

${ }^{49}$ RicCI, Edoardo, Sul principio del doppio grado di giurisdizione, en RDPC. 33 (Segunda serie), parte I (1978), p. 63. 
marco de un proceso oral y concentrado y de contacto directo e inmediato del juez con las pruebas, como es el que contempla el APCPC., resulta recomendable y hasta exigible un juicio en única instancia ${ }^{50}$.

Sin embargo, "sea constitucional o legal, sea expreso o implícito, derivado de otros principios o no, el doble grado de jurisdicción no es (y no puede ser) óbice en cuanto a la eficacia de las decisiones jurisdiccionales de primer grado, al punto de impedir y negar viabilidad a la ejecución provisoria de lo juzgado" 51 . En tal sentido, la existencia de la institución de la ejecución provisional soluciona la convivencia aparentemente conflictiva que existe entre el derecho al doble grado de conocimiento y el derecho a una tutela judicial efectiva.

\section{REGLAS TÉCNICAS EN EL ESTABLECIMIENTO DE LA EJECUCIÓN PROVISIONAL DE LA SENTENCIA}

Existen, en el derecho comparado, diversas maneras de estructurar la institución de la ejecución provisoria de la sentencia ${ }^{52}$; ello, no obstante que la circunstancia que califica la ejecución de provisional es el carácter de la sentencia más que el modo de ejecución en sís3.

Estos modelos dan cuenta de los diversos objetos específicos que pueden perseguirse con la figura analizada en este trabajo y, así, hay sistemas en que parece privilegiarse la ejecución en sí mis ma, como otros en que la ejecución provisional, en su perspectiva de realización del derecho del actor, aparece mitigada, de lo cual se desprende que el acento está puesto en lo ca u tela r más que en lo ejecutivo propiamente tal. En otros términos, se privilegia la aceleración de la actividad ejecutiva para el aseguramiento del resultado del juicio, por sobre el cumplimiento íntegro de lo resuelto por la sentencia impugnada.

Considerando lo anterior, parece conveniente dar cuenta de los aspectos más importantes que deben ser considerados por el legislador al momento de establecer un régimen de ejecución provisional. Estas reglas técnicas

${ }^{50}$ Cerino-Canova, Augusto, Realtà' e prospettive dell'appello civile, en RDPC. 33 (Segunda serie), parte I (1978), p. 93.

${ }^{51}$ Scarpinella Bueno, Cassio, Execuçao provisoria e antecipaçao da tutela (São Paulo, 1999), p. 27.

${ }^{52}$ Véase, al respecto, el acabado análisis de Hess, Buckhart, Study JAI/A3/2002/02 on making more efficient the enforcement of judicial decisions within the European Union: Transparency of a Debtor's Assets. Attachment of Bank Accounts. Provisional Enforcement and Protective Measures, disponible en: http://ec.europa.eu/justice_home/ doc_centre/civil/studies/doc/enforcement_judicial_decisions_180204_en.pdf (consulta: octubre de 2007).

${ }^{53}$ Kerameus, Konstantinos, cit. (n. 28), p. 20. 
-que implican una decisión entre, generalmente, dos alternativas de configuración-, podemos sintetizarlas en los siguientes puntos clave:

\section{Ejecución provisional "ope legis" u "ope iudicis" 54}

Un primer elemento a dilucidar está referido a la manera cómo va a activarse la ejecución provisional, si por la sola disposición de la ley, o bien mediando una autorización del juez, marcada por la discrecionalidad.

En el primero de los sistemas, denominado ope legis, el cumplimiento provisional de la sentencia deriva de la propia ley. Las facultades del juez para impedir la ejecución de una sentencia que ha sido objeto de impugnación por vía de apelación son mínimas. Su rol, fundamentalmente, consiste en verificar el cumplimiento de determinados requisitos de orden objetivo, dentro de los cuales el más importante es que la resolución sea susceptible de ejecución provisoria según la ley. Es el sistema aplicado en la legislación procesal civil italiana y española ${ }^{55}$.

En el sistema de ejecución provisional ope iudicis, es el juez quien determina, con mayor o menor discrecionalidad, la improcedencia de la ejecución provisional de la sentencia. Hablo de improcedencia, toda vez que, en principio, la sentencia sí es ejecutable provisoriamente. Por ello, para detener esta consecuencia natural, el juez atiende a determinadas pautas establecidas por la ley.

Así entonces, generalmente dos son estos criterios. El primero de ellos consiste en la acreditación de motivos graves o motivos fundados, los cuales, de concurrir, implican la suspensión de esta ejecución provisional. Estas expresiones parecen reducir el ámbito de valoración del juez a la verificación de la autenticidad del supuesto gravamen, en relación al fumus boni iuris invocado al solicitar la suspensión ${ }^{56}$.

El segundo criterio generalmente utilizado es el del daño grave o ir reparable, o daño gravísi mo. Las fórmulas basadas en este criterio se concentran sobre el concepto de periculum in mora, denunciado por quien padece la ejecución, admitiendo una valoración comparativa de los perjuicios (predominante, pero no sólo, económicos) que se provocarían a una u otra parte ${ }^{57}$.

Un ejemplo interesante del peligro en el retardo -que, en todo caso, se mitiga importantemente ante la condena de la suma reajustada y con intereses- se produce a propósito de la depreciación monetaria. La Corte de Apelaciones de Milán en 1976, señala que: "la duración del proceso

\footnotetext{
${ }^{54}$ Véase un detallado tratamiento en CARPI, Federico, cit. (n. 7), pp. 145-224.

${ }^{55}$ En Italia: CPCIt. artículos 282 y ss. En España: LECEsp., artículos 524 y ss.

${ }^{56}$ Comoglio, Luigi Paolo, cit. (n. 39), p. 432.

${ }^{57}$ Ibíd.
} 
puede efectivamente frustrar en buena parte la satisfacción del derecho controvertido cuando se expone la seria posibilidad que el tiempo necesario para el reexamen solicitado, traduzca la entidad nominalmente debida, en un bien que no satisface el derecho controvertido" 58 .

Estos distintos criterios tienen una importancia mayor de lo que pudiera parecer a simple vista. En el caso italiano, por ejemplo, hasta el año 2006, el tribunal de apelación podía disponer la suspensión total o parcial de la ejecución provisional atendiendo al criterio de graves motivos. Sin embargo, el artículo 283 CPCIt. fue modificado por la Ley No 263, de 1 de marzo de 2006, estableciéndose en la actualidad la fórmula de graves y fundados motivos, también en relación a la posible insolvencia de alguna de las partes. Cabe señalar que la misma ley añadió la posibilidad para el juez de exigir una caución a la parte que pretende la suspensión de la ejecución provisional.

\section{Solicitud de ejecución provisional sujeta a plazo.}

En este aspecto, la LECEsp. (2000) ha eliminado un requisito que, bajo la legislación anterior, sí existía. Me refiero al plazo para solicitar la ejecución provisional, y que en España era de una extensión de 6 días a contar de la notificación de la sentencia.

Se trata ésta de una decisión legislativa de relevancia. Por una parte, se ha criticado la extrema libertad que se le otorga a la parte provisionalmente vencedora en relación a la oportunidad procesal para impetrar la ejecución provisional ${ }^{59}$. Ello, si bien objetivamente atenta contra el valor de la seguridad jurídica y genera una incertidumbre en el ejecutado, no basta para echar por tierra la opción de no sujetar la ejecución provisional a un plazo para su solicitud (siendo su límite natural el fallo del recurso y la posterior ejecutoriedad de la sentencia). Esto porque, con la misma lógica, podría criticarse el entregar un plazo de años para que la parte vencedora en una sentencia firme, inste por su ejecución ${ }^{60}$.

Así entonces, considero que la solicitud de ejecución provisional, en cuanto a su oportunidad, debería estar sujeta a los mismos plazos que la

${ }^{58}$ Sentencia de la Corte de Apelaciones de Milán, de 4 de mayo de 1976, en causa caratulada "Società Sica contro Giambelli", citada por CARPI, Federico, Svalutazione monetaria, pericolo nel ritardo e provvisoria esecutorietà della sentenza, en RDPC. 33 (Segunda serie), parte II (1977), p. 312.

${ }^{59}$ En tal sentido, Cordón, Faustino, cit. (n. 42), p. 67.

${ }^{60} \mathrm{El}$ APCPC. no varía las reglas de ejecución incidental y del juicio ejecutivo, en relación con el plazo para poder iniciar uno u otro procedimiento. Véanse, al efecto, los artículos 220, en materia de ejecución incidental, y 397, en materia de prescripción de la acción ejecutiva. 
ejecución definitiva; ello, reforzando la idea que la única diferencia entre ambos institutos ejecutivos está en la ausencia de la firmeza y ejecutoriedad en el primer caso, pero en nada más.

\section{Necesidad de prestar caución por la parte que pretende ejecutar provi- sionalmente.}

La figura de la caución, en materia de ejecución provisional, tiene proyecciones en distintos aspectos estructurales de la misma. En primer lugar, en lo referente a la necesidad o no que tiene el ejecutante de prestarla, como requisito para proceder a la ejecución provisional de la sentencia. En segundo lugar, como exigencia para el ejecutante que insiste en la ejecución provisional, una vez que ha sido acogida la oposición a la misma por parte del ejecutado. Finalmente, como exigencia para el ejecutado, en caso de pretender la suspensión de la ejecución provisional de cierto tipo de resoluciones.

Es el primer aspecto mencionado -necesidad de prestar caución para ejecutar provisionalmente- el que, posiblemente, tiene mayores efectos en la utilización de la figura por parte del vencedor en una sentencia. La finalidad de la constitución de la caución es garantizar la restitución, al menos por equivalencia, en caso de ser acogido el recurso deducido contra la sentencia provisionalmente ejecutada. Ello emana del hecho que la ejecución provisional, por definición, siempre actúa bajo la sombra de una (mayor o menor) incertidumbre.

La prestación de una caución tiene diversas alternativas de configuración, pasando por su exclusión absoluta, hasta su exigencia sin petición previa de la parte ejecutada, sino que por disposición del juez. También puede optarse entre la admisión de cauciones exclusivamente dinerarias, y el ensanchamiento de las opciones de caución, como podría ser el otorgamiento de una garantía real (como una hipoteca) o de otra clase.

Ahora bien, en principio, un sistema de ejecución provisional que prescinda de la exigencia de constituir una caución parece peligroso, pues deja a la parte provisionalmente ejecutada en un pie de desigualdad en relación al ejecutante, sobre todo en miras a un eventual resultado positivo en la apelación, que se traduzca en la necesidad de restituir aquello que fue entregado en virtud de la ejecución provisional. Ello es reforzado aún más, cuando se estima que la caución, más allá de constituir una garantía de la restitución en caso de reforma de la sentencia, es un instrumento que intenta equilibrar la posición de las partes ${ }^{61}$.

Sin embargo, existen también diversas maneras de evitar esta arriesgada

${ }^{61}$ CARPI, Federico, cit. (n. 7), p. 18. 
forma de concebir la ejecución provisional. Así, por ejemplo, en España, país en que rige la ejecución provisional sin necesidad de prestar caución por parte del ejecutante, desde un punto de vista estrictamente técnico se mitigan las posibilidades de irreversibilidad de lo provisionalmente ejecutado, mediante la incorporación de la caución no en la fase de admisión de la ejecución provisional, sino que en el transcurso del procedimiento ejecutivo, y ante situaciones concretas en que aparezca la necesidad de prevenir una eventual imposibilidad de retrotraer los efectos derivados de la ejecución provisional.

En Chile, al menos según lo manifestado por el FPC en su "Informe final", se pretende seguir en este aspecto (y prácticamente en todos los demás) el mismo camino seguido por la LECEsp. (2000). Como se observa, dos son las finalidades perseguidas con esta figura. Cuando la presta el ejecutado, suspender la ejecución de una condena dineraria. Cuando la presta el ejecutante, permitir la continuación de la ejecución provisional en el caso de estimarse, en la ejecución provisional de una condena no dineraria

En mi opinión, la imposición de la caución no debería ser descartada de plano, sino, más bien, regulada prudencialmente, y caso a caso, por el tribunal encargado de conocer de ejecución provisional. No debe caerse en una especie de penalización injustificada de la parte que quien pretende ejecutar una sentencia que le ha favorecido y, para ello, deberían utilizarse criterios generales, como el del daño que puede causarse a la parte vencedora, en caso de suspenderse la ejecución provisional, así como las facultades económicas del ejecutante (por ejemplo, en el caso de la condena a pagar una determinada pensión alimenticia).

Con ocasión de este aspecto, es necesario preguntarse por qué razón debería el ejecutante provisional resarcir los daños producidos al ejecutado con la ejecución de la sentencia de primera instancia que es, posteriormente, revocada. José Da Silva Pacheco se pregunta si la reparación que debe realizar el ejecutante provisorio en caso de sentencia revocatoria está fundada sobre el concepto de culpa o sobre una presunción de culpa; o bien sobre una teoría del riesgo o sobre una responsabilidad objetiva. Se inclina el autor por esta segunda alternativa ${ }^{62}$.

Siempre en el derecho brasileño, Araken De Assis da cuenta del establecimiento de una responsabilidad objetiva de quien insta por la ejecución provisoria de la sentencia, por aplicación del principio "qui sentit commoda et incommoda sentire debet" ${ }^{\prime 3}$.

${ }^{62}$ Silva Pacheco Da, José cit. (n. 17), p. 330.

${ }^{63}$ Assis, Araken De, Manual de Execuçao (9a edición, São Paulo, 2005), p. 286. 
En Italia, ya en 1924, Alessandro Rasselli no miraba con buenos ojos esta última opción. En efecto, el autor critica "la excesiva rigidez de la teoría del riesgo, que deja perplejo en ciertos casos a los más acreditados seguidores de ésta, en cuanto parece que no se presta a admitir ninguna limitación a la responsabilidad del ejecutante, tampoco en los casos en que ello aparece como ecuánime" ${ }^{64}$. También critica la teoría de la culpa, por cuanto en el hecho y en el estado psicológico de quienes ejecutan provisionalmente una sentencia no se encuentran los elementos característicos del concepto jurídico de culpa. La ejecución provisional está expresamente autorizada por el juez y, en consecuencia, representa el ejercicio legítimo de una facultad jurídica ${ }^{65}$.

Concluye el autor, tomando una postura ecléctica, señalando que en la ejecución provisoria y el daño a resarcir existe un nexo causal. En otros términos, quien procede a la ejecución provisoria tiene en vista una ventaja económica inmediata y, si para conseguirlo ocasiona a otro un daño ilícito, es justo que soporte el peso económico, en virtud del principio ya mencionado anteriormente: qui sentit commoda et incommoda sentire debet ${ }^{66}$.

Este tema, finalmente, se vincula con el del régimen de oposición, por parte del ejecutado, dentro de la ejecución provisional de la sentencia.

\section{Régimen de oposición del ejecutado a la ejecución provisional.}

En esta materia, es necesaria una distinción previa con relación a las sentencias que pueden ser ejecutadas provisionalmente. En general, puede afirmarse que son susceptibles de esta institución las sentencias definitivas e interlocutorias que contienen pronunciamientos de condena; ello porque son las únicas que, en rigor, exigen de una actividad ejecutiva.

Siendo esta la regla general, las excepciones vienen dadas, generalmente, por sentencias recaídas en procedimientos que involucran un pronunciamiento sobre el estado civil de las personas, salvo en los aspectos netamente patrimoniales y obligacionales que surjan de dicha sentencia (como podría ser el derecho de alimentos que podría surgir con ocasión de la determinación de la paternidad). Es lo que se observa, por ejemplo, en el artículo 525 de la LECEsp. (2000).

Ahora bien, dentro de las sentencias de condena, pueden distinguirse

Cabe señalar que el autor hace referencia al artículo 588 del Código de Proceso Civil brasileño, hoy derogado. Sin embargo, la misma norma se encuentra contenida en el artículo 475-O, desde la reforma de diciembre del año 2005.

${ }^{64}$ Rasselli, Alessandro, Della provvisoria esecuzione delle sentenze e del risarcimento dei danni, en RDPC. 1, parte II (1924), pp. 239-240.

${ }^{65}$ Ibíd., p. 241.

${ }^{66}$ Ibíd., p. 243. 
aquéllas que son de co nden a din e ra ri a y las que no lo $\operatorname{son}^{67}$. En el caso español, respecto a las condenas dinerarias no se admite la oposición a la ejecución, sino sólo respecto de con cre tas actuacio nes ejecutivas del procedimiento de apremio, por estimar que ellas causarán una situación absolutamente imposible de restaurar o de compensar económicamente mediante el resarcimiento de daños y perjuicios, en caso de revocación de la sentencia recurrida. Además, se le impone al ejecutado la carga de proponer medidas ejecutivas alternativas, igualmente eficientes, pero sin que provoquen las situaciones que se pretenden evitar con la oposición a las medidas específicas que se pretenden llevar a cabo. Si no cumple con ello, o bien las medidas alternativas no son aceptadas por el tribunal, deberá constituir una caución para responder de la demora en la ejecución provisional, sin la cual no habrá posibilidad de conseguir la suspensión de la ejecución (artículo 528 LECEsp. (2000). Finalmente, en el caso de condena de una cantidad de dinero líquida, el ejecutado provisional podrá instar por la suspensión de la ejecución, consignando el total demandado, más intereses y costas causadas hasta el momento en que se consigne, para que el tribunal ponga dicha suma a disposición del ejecutante [artículo 531 LECEsp. (2000)].

En el caso de las sentencias de co nden a no din e ra ria, la oposición a la ejecución sólo será admitida cuando se acredite que será imposible o de extrema dificultad, atendida la naturaleza de las actuaciones ejecutivas, restaurar la situación anterior a la ejecución provisional o compensar económicamente al ejecutado mediante la indemnización de daños, en caso de revocarse la sentencia [artículo 528 LECEsp. (2000)]. En este caso, y para continuar el procedimiento ejecutivo, será el ejecutante quien deberá otorgar una caución que sirva como garantía de la restitución en caso de revocación, o de la indemnización de los daños y perjuicios en caso que la restitución sea imposible [artículo 529 LECEsp. (2000)].

\section{CASOS DE EJECUCIÓN PROVISIONAL EN LA LEGISLACIÓN PROCESAL CHILENA Y RÉGIMEN PROPUESTO EN EL "ANTEPROYECTO DE CÓDIGO PROCESAL CIVIL" CHILENO}

\section{Casos de ejecución provisional en el derecho procesal civil chileno.}

Como fue anticipado al comenzar este trabajo, la ejecución provisional no es extraña a nuestro ordenamiento procesal civil. Así, aunque de manera inorgánica, funcionalmente se aplica en varias hipótesis contempladas tanto en el CPC., como en otras leyes, siendo una manifestación de tutela

${ }^{67}$ Es lo que ocurre en el caso español, aunque no es así en otras legislaciones, como la brasileña. 
anticipada en el derecho nacional. La ejecución en estos casos se ciñe a las reglas generales.

Se trata de todos los casos en que el recurso de apelación es concedido en el solo efecto devolutivo, como ocurre en casos como los siguientes:

a) Juicio ejecutivo. El artículo 475 CPC., deja abierta la posibilidad de proceder a la ejecución de la sentencia de pago dictada en el juicio ejecutivo, a pesar que haya sido apelada dicha resolución. No obstante, para que opere esta ejecución es necesaria la prestación de una caución por parte del ejecutante, para asegurar los resultados derivados del eventual acogimiento del recurso. Se sigue en este campo la lógica tradicional de exigir una caución previa a la parte que pretende ejecutar una sentencia que ha sido objeto de algún medio de impugnación.

b) Recurso de casación. El artículo 773 del CPC. comienza sentando la regla general en materia de interposición de recurso de casación: no se suspende la ejecución de la sentencia, salvo que, de proceder a dicha ejecución, la sentencia que acoja el recurso no pueda cumplirse, lo que ocurrirá en situaciones en que se vean involucradas, fundamentalmente, cuestiones vinculadas al estado civil de las personas. En prácticamente el resto de los $\operatorname{casos}^{68}$, la única opción que tiene el recurrente de casación es solicitar del vencedor la prestación de una fianza de resultas, regulada por el tribunal que pronunció la sentencia recurrida. Este derecho debe ejercerse conjuntamente con la interposición del recurso, pero en solicitud separada.

Los dos casos hasta ahora mencionados difieren importantemente. En el primero de ellos, la prestación de una caución constituye una carga para la parte que desea ejecutar, de la cual la ley no dispensa, sino que establece como un requisito previo para la ejecución. En el segundo caso, el otorgamiento de la fianza de resultas constituye una carga sujeta a que el recurrente de casación la haga valer; es decir, la ley no impone dicha fianza como un requisito previo e indispensable para proceder a la ejecución, de manera tal que si el recurrente omite solicitarla -en la única oportunidad procesal que tiene para ello-, la parte vencedora podrá instar por la ejecución sin limitación alguna.

Lo anterior, amén de confirmar el carácter extraordinario que tiene el recurso de casación, es interesante porque muestra dos modelos distintos de ejecución provisional.

c) Juicio sumario. En principio, la sentencia definitiva pronunciada en el juicio sumario es apelable en ambos efectos, según lo que dispone el

${ }^{68}$ Salvo que el recurso de casación sea interpuesto por el demandado en los juicios ejecutivos, posesorios, de desahucio y de alimentos. 
artículo 691 CPC. La jurisprudencia ${ }^{69}$ se encuentra conteste en que esta norma prima sobre la contenida en el artículo 194 No 1 CPC. (que señala que la apelación, en los casos de resoluciones dictadas contra el demandado en juicios ejecutivos y sumarios, se concede en el solo efecto devolutivo), por el principio de la especialidad.

Una particularidad contenida en el artículo 691 consiste en la posibilidad de ejecutar la sentencia definitiva de primera instancia, a pesar de haber sido objeto de apelación, cuando, de concederse en ambos efectos, los resultados de la sentencia puedan verse eludidos. Sin embargo, no se regulan los parámetros que el juez debería aplicar para concluir que lo dispuesto en la sentencia definitiva pueda ser burlado por la concesión del recurso en ambos efectos.

Así entonces, el juez, junto con conceder el recurso de apelación, podría limitarlo sólo al efecto devolutivo, consignando las razones por las cuales estima que la concesión del recurso en ambos efectos significaría eludir los resultados de la sentencia. Ante ello (y también en el caso donde se concediera en ambos efectos el recurso, y el apelado estimara que se burlan los resultados de la sentencia) procedería sólo el recurso de hecho.

Ahora bien, la justificación del procedimiento sumario supone, generalmente, la existencia de una acción que requiera de rápida tramitación para ser eficaz, por lo que habría que ponderar la existencia de antecedentes que agraven particularmente esta característica; ponderación sujeta al solo criterio del juez de la instancia o, en caso de existir un recurso de hecho, a la Corte de Apelaciones respectiva.

Finalmente, y a pesar de que suele no ser utilizada esta forma de ejecución provisional, es necesario consignar que se trata del único ejemplo del CPC. en que no se exige caución alguna para ejercerla.

d) Juicios posesorios. El artículo 550 CPC. prescribe que las apelaciones de las resoluciones pronunciadas en los juicios posesorios serán concedidas en el solo efecto devolutivo, lo que es armónico con el carácter particularmente concentrado que, al menos en teoría, tiene el procedimiento al que se sujetan dichos pleitos. La excepción consiste en que no se dé lugar al fallo, caso en el cual la apelación será concedida en ambos efectos, privilegiando, por ende, al demandante por sobre el demandado.

e) Sentencias interlocutorias. Aunque no se trata de sentencias

${ }^{69}$ V. gr., Corte Ap. de Santiago, 18 de enero de 2002, causa rol No 9524-2001, No LexisNexis: 23951; 2 de abril de 2001, causa rol No 270-2001, No LexisNexis: 21276; 2 de abril de 2001, causa rol No 821-2001, No LexisNexis: 21297; 3 de enero de 2001, causa rol No 9007-2000, No LexisNexis: 21225; 20 de octubre de 2000, causa rol No 6801-2000, No LexisNexis: 21126; 27 de septiembre de 2000, causa rol No 5156-2000, No LexisNexis: 21074. 
definitivas, las sentencias interlocutorias pueden contener pronunciamientos de condena a favor de una de las partes, como podría ser la que recae sobre el incidente especial de costas. Conforme lo dispuesto en el artículo 194 CPC., estas resoluciones son susceptibles de apelación, la que será concedida en el solo efecto devolutivo. Lo mismo es predicable respecto de autos y decretos cuando, excepcionalmente, puedan ser objeto de impugnación por la vía del recurso de apelación.

f) Juicios con ocasión del contrato de arrendamiento. En esta materia, 3 son los artículos que deben tenerse a la vista. El primero de ellos es el artículo 606 CPC. - ubicado dentro del título que regula los juicios especiales del contrato de arrendamiento-, que establece la concesión de la apelación, en el solo efecto devolutivo, respecto de las sentencias en que se ratifique el desahucio o se disponga el lanzamiento del arrendatario, se dé lugar al derecho de retención a favor del arrendatario o se resuelva la restitución de la cosa arrendada.

El segundo artículo es el 614, en materia de juicios por terminación inmediata del arrendamiento, y que otorga el recurso de apelación en el solo efecto devolutivo, respecto de la sentencia que diere lugar a la terminación del contrato.

El último precepto se encuentra fuera del CPC.; concretamente en la Ley No 18.101 sobre arrendamiento de predios urbanos. El artículo 8 de dicha ley, en su No 9, establece que todas las apelaciones que se deduzcan en este juicio sumario especial, serán concedidas en el solo efecto devolutivo. La regla original contenida en la ley en comento era la contraria, toda vez que se remitía, en este y otros aspectos, a la regulación del juicio sumario en el CPC. La modificación, al igual que la mayoría de las incorporadas por la Ley No 19.866, de 11 de enero de 2003, obedeció al deseo de facilitar el acceso a la ejecución para el arrendador, quien, bajo el régimen anterior, debía soportar todo el tiempo del recurso de apelación interpuesto por su arrendatario, recurso que, sobre todo en una materia como la comentada, tenía una innegable conveniencia práctica, pues permitía hacerse de un considerable tiempo extra con el inmueble arrendado.

g) Procedimiento de expropiación por causa de utilidad pública o interés social o nacional. El artículo 921 CPC., que forma parte de la regulación procesal de la expropiación por causa de utilidad pública, sienta el principio general que toda apelación será concedida en el solo efecto devolutivo. Criterio similar es el establecido por el Decretoley No 2186 de 1978, en su artículo 40, salvo los casos de la sentencia que fije el monto definitivo de la indemnización para el expropiado, y de aquélla pronunciada en el marco de la intervención, en el procedimiento de expropiación, de un tercero, que invoque derechos reales sobre el bien 
expropiado -constituidos con anterioridad al acto expropiatorio-, o que sea acreedor con una resolución judicial -anterior a la fecha del acto expropiatorio- a su favor, que embarace o limite el derecho real de dominio sobre el bien, o las facultades inherentes al dominio.

\section{Situaciones que se producen al revocarse total o parcialmente la sentencia} provisionalmente ejecutada.

Habiendo quedado claro que la ejecución provisional es una institución con presencia inorgánica en nuestra actual legislación, naturalmente surge la interrogante en torno a las diversas situaciones que se producen en los casos en que la resolución provisionalmente ejecutada es revocada, sea total o parcialmente, por efecto de la acogida al recurso interpuesto en su contra.

Evidentemente no existe una solución única, aplicable a la generalidad de los casos antes vistos; por el contrario, debe atenderse a cada hipótesis en particular ${ }^{70}$.

Así entonces, en el caso de la ejecución de la sentencia de pago en el juicio ejecutivo la solución se ve más sencilla, toda vez que la parte interesada en dicha ejecución deberá, previamente, haber prestado una caución para asegurar los resultados de un recurso de apelación que sea acogido. Ahora, si dicha caución no fuese en definitiva suficiente para el reintegro de la situación anterior a la ejecución provisional de la sentencia apelada, pienso que el ejecutado provisional no tendría alguna vía complementaria para exigir la reparación de estos daños adicionales, toda vez que la fuente de la obligación del ejecutante, de resarcir dichos perjuicios, es una norma que impone al juez una estimación anticipada de estos, y es sólo con respecto a dicha avaluación que el interesado en la ejecución tomará la decisión de instar o no en ella, previendo una pérdida eventual, hasta un límite determinado. Más allá de ello, no existe fuente alguna que obligue a la reparación de los daños que excedan dicho margen.

Misma solución es aplicable en el caso del recurso de casación, siempre y cuando la fianza de resultas sea solicitada oportunamente por el recurrente.

Ahora bien, las complicaciones surgen respecto de los demás casos enumerados en el acápite anterior. En efecto, no existe norma que, directamente, regule la manera de ejecutar o realizar lo dispuesto por una sentencia revocatoria de la provisionalmente ejecutada.

${ }^{70}$ Como se verá inmediatamente, el APCPC tampoco regula en concreto este tema, sino que da una fórmula amplia que permite al juez tomar todas las medidas necesarias para retrotraer la situación que exista entre las partes una vez acogido el recurso contra la sentencia provisionalmente ejecutada. 
Para los efectos de solucionar este punto, y dentro de nuestro inhóspito panorama, pienso que es razonable someter la tramitación de esta petición a las normas generales en materia de ejecución. Así entonces, una alternativa -aplicable en el mismo juicio a petición del ejecutado provisional, dentro de un año desde que las prestaciones ordenadas por la sentencia se hicieran exigibles-, sería utilizar el procedimiento de ejecución incidental contemplado en los artículos 233 y siguientes CPC. Para los efectos de las restituciones que fuesen procedentes, debería acudirse al derecho común y aplicar, en consecuencia, las normas relativas a las restituciones mutuas, previstas en los artículos 904 y siguientes CC. En tal caso, pienso que siempre deberá tenerse al ejecutante provisional como poseedor de buena fe, en el entendido que, al instar por la ejecución provisional, la parte demandante no hace más que ejercer, legítimamente, una facultad jurídica.

Una segunda alternativa, siempre en el contexto de las normas generales, sería instar por la restitución de la situación existente con anterioridad a la ejecución provisional, precisamente mediante la incoación de un nuevo juicio ejecutivo, teniendo como título a la sentencia revocatoria.

No obstante la solución propuesta, es claro que su implementación resulta, en cierto modo, forzada, y da cuenta del problema que existe detrás: la inexistencia de un régimen general de ejecución provisional, que reglamente el iter procesal en caso de revocación de la sentencia ejecutada bajo este estatuto.

\section{La ejecución provisional en el "Anteproyecto de Código Procesal Ci-} vil'.

Resulta hasta cierto punto desconcertante observar que no hay una correlación entre el énfasis que se le da a la ejecución provisional de las sentencias en el Informe Final del FPC, y la escasísima -por no decir, derechamente, nula- regulación que, de la institución, se encuentra en el APCPC.

El artículo 18 APCPC., ubicado dentro del primer título del texto, denominado como Principios Básicos, consagra la regla general de la ejecución provisoria de las sentencias definitivas de interlocutorias ${ }^{71}$.

Posteriormente, el artículo 222 del mismo anteproyecto, situado en la regulación de la ejecución incidental de las sentencias,

\footnotetext{
${ }^{71}$ Artículo 180: "Cumplimiento de resoluciones judiciales": "Las sentencias definitivas e interlocutorias podrán cumplirse una vez que se encuentren firmes o ejecutoriadas, debiendo el tribunal ordenar todas las diligencias que fueren pertinentes para satisfacer la pretensión reconocida en el fallo./ Las sentencias definitivas e interlocutorias podrán cumplirse provisionalmente, aun cuando no se encontraren firmes o ejecutoriadas, salvo que el legislador disponga expresamente lo contrario".
} 
tangencialmente menciona la necesidad de rendir caución para ejecutar la sentencia, así como señala que dicha caución será alzada una vez que la sentencia adquiera el carácter de firme o ejecutoriada ${ }^{72}$.

El inciso final del mismo precepto establece una excepción a la regla general de rendir caución para proceder a la ejecución provisional ${ }^{73}$.

Luego, el artículo 228, de forma meramente enunciativa, establece el régimen al que se sujetará una sentencia provisionalmente ejecutada, $y$ que haya sido revocada, modificada o anulada por una sentencia de grado superior $^{74}$.

El círculo se cierra con el No 1 del artículo 395, que es la norma con la que comienza el estatuto del juicio ejecutivo. Dicho precepto indica que el cumplimiento de las sentencias que causan ejecutoria (es decir, provisionalmente ejecutables) debe ceñirse, exclusivamente, al procedimiento incidental, que no difiere mayormente del que actualmente se encuentra vigente en el procedimiento civil. De ello, se extraen conclusiones tales como que la ejecución provisional puede instarse en el plazo de un año desde que la ejecución se hizo exigible.

${ }^{72}$ Los incisos $3^{\circ}$ y $4^{\circ}$ de la norma citada indican lo siguiente: Artículo 2220: "Procedimiento para proceder a la ejecución": "El tribunal deberá establecer al decretar la ejecución la necesidad de constituir una caución efectiva para proceder al cumplimiento de una sentencia que causa ejecutoria, de manera de asegurar la restitución de lo cumplido en caso de revocarse o modificarse el fallo por parte del que solicita la ejecución./ Dicha caución se alzará una vez que la sentencia cuya ejecución provisional se solicita haya adquirido el carácter de firme o ejecutoriada".

73 "No será necesaria la rendición de caución previa por el que hubiere obtenido en juicio para proceder a la ejecución de una sentencia que causa ejecutoria cuando se pretendiere hacer cumplir una resolución que se fundamente en un avenimiento o conciliación, se haya dictado existiendo un allanamiento del demandado; se hubiere pronunciado en juicios de arrendamiento, comodatos precario, querellas posesorias o constitución de servidumbres; o se pretendiere obtener el pago mensual de pensiones o prestaciones indemnizatorias no superiores a 56 Unidades de Fomento mensuales" (sic.)

${ }^{74}$ Artículo $228^{\circ}$ : "Supresión de la ejecución provisional, derecho a la devolución y la indemnización por daños y perjuicios": "La ejecución queda anulada con la pronunciación de una sentencia que revoque, modifique o anula el fallo que se haya ejecutado provisionalmente. Si una sentencia ejecutada provisionalmente es revocada, modificada o anulada, el tribunal deberá disponer que se realicen todas las actuaciones para retrotraer el proceso al estado anterior a la ejecución, sin perjuicio que quien hubiere solicitado su ejecución además de proceder a la devolución de lo que hubiere percibido estará obligado a compensar el daño que se le ha ocasionado al demandado con la ejecución de la sentencia o con el otorgamiento de la caución otorgada para evitar la ejecución. El demandado puede hacer valer el derecho de indemnización por daños y perjuicios en el proceso en el cual se solicitó la ejecución dentro del plazo de un año desde que se hubiere dictado la sentencia que revoco, modificó o anulo la sentencia ejecutada provisionalmente, y su petición indemnizatoria se tramitará de acuerdo a las reglas de los incidentes". 
Ahora bien, el régimen antes indicado dista bastante del propuesto por el FPC en su Informe Final. En efecto, en éste se sientan las bases de la ejecución provisional de la sentencia definitiva en términos prácticamente idénticos a la regulación que la LECEsp. (2000) contempla para esta institución, y que ya han sido esbozados a lo largo del presente trabajo. Se trata, por ende, de una desarmonía que será necesario remover en vistas del proyecto definitivo.

Finalmente, un aspecto que no puede dejarse pasar es que el APCPC. establece, en idénticos términos que nuestro actual CPC., la posibilidad que tienen los tribunales de apelación de decretar órdenes de no innovar ${ }^{75}$, institución que, como se sabe, viene a moderar los efectos que se derivan de la concesión de un recurso de apelación en el solo efecto devolutivo. Esta situación, ya en teoría, plantea interrogantes de envergadura, sobre todo en vistas del adecuado desarrollo de la figura de la ejecución provisional de las sentencias. Por ende, es un tópico que exige una estructuración que no deje sólo en el papel el instituto estudiado en estas páginas

\section{La ejecución provisional en el Derecho administrativo.}

No puede concluir el análisis de este trabajo sin hacer una mención, aunque sea tangencial, a la ejecución provisional en el área del derecho administrativo. Así entonces, si en el derecho procesal civil la institución de la ejecución provisional es desconocida en cuanto estructura orgánica y de aplicación general, no ocurre lo mismo al trasladarnos al procedimiento administrativo, en donde el efecto ejecutivo inmediato de los actos de la Administración es un principio tradicionalmente aceptado y, hoy, expre-

${ }^{75}$ Artículo 351: "Concesión de apelación en el solo efecto devolutivo": "Cuando la apelación proceda sólo en el efecto devolutivo, seguirá el tribunal inferior conociendo de la causa hasta su terminación, inclusa la ejecución de la sentencia definitiva./ Si se revocare el fallo que se hubiere cumplido, deberá el tribunal de primera instancia decretar todas las medidas para que se restituya a las partes a la posición en que se encontraban con anterioridad a su ejecución de la sentencia./ El tribunal de alzada, a petición del apelante y mediante resolución fundada, podrá dictar orden de no innovar./ La orden de no innovar suspende los efectos de la resolución recurrida o paraliza su cumplimiento, según sea el caso. El tribunal podrá restringir estos efectos por resolución fundada./ Los fundamentos de las resoluciones que se dicten de conformidad a este inciso no constituyen causal de inhabilidad./ Las peticiones de orden de no innovar serán distribuidas por el Presidente de la Corte, mediante sorteo, entre las salas en que esté dividida y se resolverán en cuenta. Decretada una orden de no innovar, quedará radicado el conocimiento de la apelación respectiva en la sala que la concedió y el recurso gozará de preferencia para figurar en tabla y en su vista y fallo". 
samente establecido en la LBPA., como manifestación de la denominada autotutela administrativa ${ }^{76}$.

La LBPA., en efecto, sienta el régimen general de ejecutividad inmediata de los actos administrativos, ejecución que, por lo demás, es instada por la propia Administración. La primera de las normas que inciden al respecto es la contenida en el artículo 51, que consagra la regla de la in media ta ejecutoriedad del acto administrativo. Debe hacerse presente la confusión en que incurre el legislador, toda vez que toma como sinónimos los conceptos de eficacia con el de ejecutoriedad (lo que en derecho procesal civil correspondería al concepto de cosa juzgada), cuando ya hemos visto que son ideas absolutamente distintas.

Hecha esta aclaración, el artículo 51 LBPA. se conecta con lo preceptuado en el artículo 57 de la misma ley, que señala que la interposición de un recurso administrativo no suspenderá la ejecución del acto impugnado. La situación contraria se producirá cuando la autoridad llamada a conocer el recurso, a petición fundada del interesado, disponga la suspensión de este efecto ejecutivo inmediato cuando estime que el cumplimiento del mismo acarree un daño irreparable, o bien, haga imposible el cumplimiento de lo que se decrete una vez acogido el recurso.

Hay que añadir, no obstante, que esta facultad de suspender la ejecución del acto es "sin perjuicio de la responsabilidad de la autoridad por los daños producidos, al no declarar la suspensión y, en definitiva, fuere declarado dicho acto como contrario a derecho"77. Además, debe vincularse lo señalado por el artículo en cuestión con el inciso final del artículo 3 LBPA., el cual, además de establecer la presunción de legalidad del acto administrativo, dispone también que la suspensión de sus efectos podrá provenir tanto de la propia Administración (órgano que conozca del recurso administrativo) como del juez que conozca de la reclamación por vía jurisdiccional.

La supresión del efecto suspensivo de los recursos administrativos es una manifestación de dos principios que lo regulan: de ejecu t o riedad y de ej ecu tividad de la decisión administrativa. Dichos principios tienen por fundamento, por una parte, el principio más general de la legitimidad

${ }^{76}$ Ferrada Bórquez, Juan Carlos, Las potestades y privilegios de la Administración Pública en el régimen administrativo chileno, en Revista de Derecho de la Universidad Austral de Chile XX (Valdivia, 2008) 2, p. 82: "En el fondo, se trata de reconocer a la Administración del Estado una potestad de autotutela declarativa y ejecutiva que le permite dotar a sus actos de una potencia y eficacia excepcionales dentro del orden jurídico”.

${ }^{77}$ Cordero Vega, Luis, El procedimiento administrativo (Santiago, 2003), p. 175. 
del acto administrativo (o de presunción de legalidad), que se traduce en una inversión de la carga de la prueba, en contra del administrado. Por otra parte, se encuentra en la intención del ordenamiento jurídico de evitar que los actos de la Administración, en teoría orientados a la satisfacción de necesidades públicas, encuentren obstáculos que impidan la obtención íntegra de dicha finalidad ${ }^{78}$. Vinculado con esto último, "si algo constante se puede afirmar respecto de los atisbos de regulación que asume nuestro legislador en materia administrativa es lo siguiente: Si lo haces, es malo, si no lo haces es peor"79.

La referencia a la ejecución provisional en el ámbito del procedimiento administrativo no tiene una finalidad meramente comparatística. Más allá de ello, lo importante es extraer argumentos que sirvan para fundar y apoyar la instauración del mismo principio general en materia de procedimiento civil. El más sólido de dichos argumentos, sin lugar a dudas, es el siguiente: si en materia de administración pública los actos emanados de la misma gozan de una presunción de legalidad, presunción que, a su vez, justificaría su carácter inmediatamente ejecutivo; con mayor razón podría predicarse lo mismo de una sentencia definitiva de primera instancia, que es el producto del seguimiento y observancia de una serie de etapas en las que se garantiza la igualdad de oportunidades para las partes del conflicto y que, en comparación al procedimiento administrativo, contiene mayores exigencias. Consecuencialmente, la sentencia tiene un mayor grado de certidumbre, a priori, que un acto emanado de una autoridad administrativa que, simultáneamente, es la principal interesada en su ejecución.

En otros términos, la sentencia judicial, en relación al acto administrativo, cuenta con mayores garantías previas de legitimidady, por ende, más allá de la finalidad perseguida por la actividad administrativa, nada justifica que el segundo cuente con una efectividad inmediata y la primera no.

\section{COMENTARIOS FINALES}

La institución procesal de la ejecución provisional tiene proyecciones en distintos campos, lo que hace de ella una atractiva figura para estudiar. Lo primero es señalar, que esta manera de concebir la ejecución -desde una perspectiva panorámica y sistémica- exige, en primer lugar, tener el

${ }^{78}$ Ibíd., pp. 175-176.

${ }^{79}$ Cordero Quinzacara, Eduardo, Eficacia, extinción y ejecución de los actos administrativos en la ley $N^{o} 19.880$, en VV. AA, Acto y Procedimiento Administrativo. Actas de las Segundas Jornadas de Derecho Administrativo (Valparaíso, 2007), p. 110. 
respaldo de un proceso en que se garantice, sobre todo, un real contacto del tribunal con las pretensiones y las pruebas aportadas por las partes. Ello incide en una mejor y más certera resolución del asunto sometido al conocimiento del juez y, por ende, en una menor posibilidad de reforma a través de los medios procesales de impugnación; medios que, personalmente, considero que no pueden ser excluidos de un sistema procesal sin renunciar, importantemente, al objetivo de la obtención de la decisión más justa posible.

Vinculado con lo último señalado, y desde un punto de vista estrictamente lógico, comparto la opinión doctrinal que ve en la ejecución provisional una manifestación de la distribución del soporte de las consecuencias que se derivan de los tiempos procesales. Si en el marco de una instancia donde el contacto del juez con el conflicto es directo e inmediato, parece razonable que el acto conclusivo de dicha instancia cuente, a priori, con fuerza para poder ser llevada a la realidad, independientemente de la impugnación, toda vez que ésta, estando dirigida a una situación que, en nuestro país al menos, es estadísticamente excepcional -la reforma o revocación de la sentencia-, no puede dejar en un exagerado suspenso lo resuelto por un tribunal que, atendida la manera que tiene de conocer de un asunto, tiene menores posibilidades de incurrir en errores sustanciales, que deban ser corregidos por la vía recursiva. Ello, empero, dejando fuera de la discusión los errores de derecho en los que puede incurrir el juez al pronunciar su sentencia. Por lo demás, ha quedado de manifiesto que, funcionalmente, esta figura existe en nuestro ordenamiento jurídico desde hace ya bastante tiempo, independientemente que se utilice frecuentemente en la práctica.

En lo referente al APCPC., pareciera que la omisión del tratamiento particular de la ejecución provisional de la sentencia no es deliberada, sino que producto de un descuido involuntario, sobre todo cuando se considera lo manifestado por el FPC, en cuanto la figura de la ejecución provisional, en conjunto con la del procedimiento monitorio, son dos ejes de la concreción de una tutela judicial efectiva. No obstante ello, llama la atención el establecimiento, en idénticos términos en que existe actualmente, de la institución de la orden de no innovar, situación que podría desajustar un régimen de ejecución provisional de las sentencias, confiriéndole a éste, quizás sin quererlo, un carácter de sistema ope iudicis cuando, a la luz de lo observado en el FPC y en el APCPC., la intención es optar por uno que funcione ope legis.

Con relación a las finalidades perseguidas con la institución, pienso que debería descartarse la de disuadir la interposición de recursos injustificados. Ejecución provisional y cognición definitiva no son antónimos, sino que pueden ser, perfectamente, objetivos complementarios. Además, es bas- 
tante discutible que pueda atribuirse a esta institución el mentado carácter disuasivo, toda vez que, desde un punto de vista lógico, es sostenible que el deudor querrá, posiblemente en la mayoría de los casos, agotar todos los medios de impugnación que estén a su disposición. Así es probado, además, por un estudio empírico llevado a cabo en un país donde existe un régimen de ejecución provisional amplio y de fácil acceso.

Mayor efecto disuasivo podría tener, por ejemplo, un aumento en los costos del recurso de apelación, sea por la vía de los honorarios profesionales del abogado conductor del juicio, sea por la instauración de tasas para acceder a los recursos procesales, y otras vías directamente destinadas a ese objetivo.

[Recibido el 28 de septiembre y aprobado el 13 de octubre de 2008]

\section{BIBLIOGRAFÍA}

Assis, Araken De, Manual de Execuçao (9a edición, São Paulo, 2005).

Barros Leonel, Ricardo De, A eficacia imediata da sentença e as reformas do Código de Processo Civil, en Revista del Proceso 119 (São Paulo, 2005), pp. 117-138.

CABALLOL, Luis, La ejecución provisional en el proceso civil (Barcelona, 1993).

Carnelutti, Francesco, Instituciones del Proceso Civil (Buenos Aires, 1960), I-III.

Carnelutti, Francesco, Sistema de Derecho Procesal Civil (Buenos Aires, 1944),IIV.

CARPI, Federico, La provvisoria esecutorietà della sentenza (Milano, 1979).

CARPI, Federico, Svalutazione monetaria, pericolo nel ritardo e provvisoria esecutorietà della sentenza, en RDPC. 32 (Segunda serie), parte II (Milano, 1977), pp. 312 $-326$.

Cerino-Canova, Augusto, Realtà' e prospettive dell'appello civile, en RDPC. 33 (Segunda serie), parte I (Milano, 1978), pp. $92-98$.

Comoglio, Luigi Paolo, Il doppio grado di giudizio nelle prospettive di revisione costituzionale, en RDPC. 59 (Segunda serie), parte 2 (Milano, 1999), pp. 317-334.

Comoglio, Luigi Paolo, L'esecuzione provvisoria della sentenza di primo grado, en VV.AA; Le Riforme della giustizia civile ${ }^{2}$ (2a edición, Torino, 2000), pp. 415437.

Cordero Quinzacara, Eduardo, Eficacia, extinción y ejecución de los actos administrativos en la ley $N^{o}$ 19.880, en VV.AA., Acto y Procedimiento Administrativo. Actas de las Segundas Jornadas de Derecho Administrativo (Valparaíso, 2007).

Cordero Vega, Luis, El procedimiento Administrativo (Santiago, 2003).

Cordón Moreno, Faustino, El proceso de ejecución (Navarra, 2002).

de la Oliva Santos, Andrés - Díez-Picaso Giménez, Ignacio - Vegas Torres, Jaime, Derecho Procesal Civil: Ejecución forzosa. Procesos especiales (3a edición, Madrid, 2005).

Ferrada Bórquez, Juan Carlos, Las potestades y privilegios de la Administración Pública en el régimen administrativo chileno, en Revista de Derecho de la Universidad Austral de Chile XX (Valdivia, 2008) 2, pp. 69 - 94. 
FINZI, Enrico, Questioni controverse in tema di esecuzione provvisoria, en RDPC. 3, parte I (Milano, 1926), p. 44 - 51.

GozAínI, Osvaldo, La ejecución provisional en el proceso civil, en RPDP. 3 (Lima, 1998), pp. 79-99.

Hess, Buckhart, Study JAI/A3/2002/02 on making more efficient the enforcement of judicial decisions within the European Union: Transparency of a Debtor's Assets. Attachment of Bank Accounts. Provisional Enforcement and Protective Measures, disponible en World Wide Web: http://ec.europa.eu/justice_home/doc_centre/ civil/studies/doc/enforcement_judicial_decisions_180204_en.pdf (consulta: octubre de 2007).

Hinojosa Segovia, Rafael - Palomo Vélez, Diego, La apuesta de la nueva Ley de Enjuiciamiento Civil Española por la revalorización de la importancia del enjuiciamiento de primer grado: La nueva regulación de la ejecución provisional de las sentencias, en Ius et Praxis 2 (Talca, 2006), pp. 123-162.

Kerameus, Konstantinos, Enforcement Proceedings, en Capelletti, Mauro (editor), International Encyclopedia of Comparative Law (Dordrecht, 2002), XVI, cap. 10, pp. 19-26.

Liebman, Enrico Tulio, Processo de Execuçao (São Paulo, 1968).

Liebman, Enrico Tulio, Sentenza e Cosa Giudicata: recente polemiche, en RDPC. 35 (Segunda serie), parte I (Milano, 1980), pp. 1-25.

Marinoni, Luiz Guilherme, $A$ antecipaçao da tutela (4a edición, São Paulo, 1998).

Marinoni, Luiz Guilherme, A execuçao "provisória" da sentença, en MARINONI, Luiz Guilherme - DiDier, Fredie (coordinadores), A segunda etapa da reforma processual civil (São Paulo, 2001).

Micheli, Gian Antonio, La tutela del diritto di credito nel processo esecutivo, en VV.AA., Atti del Congresso internazionale di Diritto Processuale Civile (Padova, 1953), pp. 90-106.

Ortells Ramos, Manuel, Derecho Procesal Civil (6a edición, Navarra, 2005).

Pérez Ragone, Álvaro, El Acceso a la Tutela Ejecutiva del Crédito, en Silva, José García, José - Leturia, Francisco (editores), Justicia Civily Comercial: una reforma pendiente. Bases para diseño de la Reforma Procesal Civil (Santiago, 2006).

Pérez Ragone, Álvaro, Introducción al estudio de la tutela anticipatoria, en Revista del Proceso 81 (São Paulo, 1999), pp. 135-140.

Ramos Romeu, Francisco, ¿Reduce realmente la ejecución provisional la interposición de recursos injustificados?, disponible en World Wide Web: http://www.indret.com/ pdf/385_es.pdf (consulta, agosto de 2007).

Rasselli, Alessandro, Della provvisoria esecuzione delle sentenze e del risarcimento dei danni, en RDPC. 1, parte II (Milano, 1924), pp. 239-247.

RICCI, Edoardo, Sul principio del doppio grado di giurisdizione, en RDPC. 33 (Segunda serie), parte I (Milano, 1978), pp. 59-85.

Rocco, Ugo, Trattato di Diritto Processuale Civile (Torino, 1959).

Romero Seguel, Alejandro, Curso de Derecho Procesal Civil. La acción y la protección de los derechos (Santiago, 2006), I.

Romero Seguel, Alejandro, La cosa juzgada en el proceso civil chileno. Doctrina y jurisprudencia (Santiago, 2002).

Salgado Carrero, Celestino, El derecho a la ejecución de las sentencias como manifestación del derecho fundamental a la tutela judicial efectiva, en Revista del Poder Judicial 51 (Madrid, 1998), pp. 69-136. 
SATta, Salvatore y PunzI, Carmine, Diritto processuale civile (13a edición, Padova, 2004).

Scarpinella Bueno, Cassio, Execuçao provisoria e antecipaçao da tutela (São Paulo, 1999).

Silva Pacheco Da, José, Açoes executivas e execuçao de sentença (Río de Janeiro, 1957).

VV.AA., "Informe final" del Foro para la Reforma Procesal Civil Chilena (documento sin editar). 